\title{
Symptoms Essential to the Experience of Sodium Lactate-Induced Panic
}

Raymond R. Goetz, Ph.D., Donald F. Klein, M.D., and Jack M. Gorman, M.D.

We report on subjective ratings and symptoms experienced before and during sodium lactate infusion by patients with panic disorder or agoraphobics with panic attack (DMS-III-R criteria). Symptoms were assessed using the Acute Panic Inventory (API). During the lactate infusion $59 \%$ of the patients were rated by an attending psychiatrist as having experienced lactate-induced panic attacks. Patients experiencing lactate-induced panic attacks overwhelmingly rated this experience as very similar to their typical naturally occurring attacks.

Among the individual API symptoms items at baseline (prelactate) only Afraid in general $(r=0.26)$ was significantly, but not strongly, correlated with the panic response. Controlling for baseline symptom levels, the most robust partial correlations of symptomatic increment with panic were Desire to flee (0.70), Fear of losing control (0.57), Afraid in general (0.49), and Dyspnea (0.48). Using a dichotomized symptom increment greater than 1, 13 of 29 API items indicated a panic response to lactate infusion; the best were Dyspnea, Feeling confused, Afraid in general, Difficulty speaking, Difficulty concentrating, Desire to flee, and Fear of losing control.

A logistic regression analysis showed that among baseline measures, Afraid in general and Feeling confused significantly predicted panic. For dichotomized change scores, Afraid in general, Dyspnea, and Dizziness/ lightheadedness significantly indicated panic. In these analyses three symptom items stand out as the most predictive and revealing of panic to lactate infusion: Afraid in general, Dyspnea, and Desire to flee. These results are discussed in the context of Klein's (1993) suffocation false alarm theory of panic. [Neuropsychopharmacology 14:355-366, 1996]
KEY WORDS: Panic disorder; Chemically induced and symptoms

It has been hypothesized that the panic attack as it occurs in panic disorder often represents a false suffocation alarm (Klein 1993). The initial phase of the false suffocation alarm is an acute sensation of dyspnea accompanied by an increase in tidal volume, anteceding the panic attack. Katerndahl (1988) also has indicated

From the Department of Therapeutics (RRG, DFK) and the Department of Clinical Psychobiology (JMG), New York State Psychiatric Institute and the Department of Psychiatry, Columbia University College of Physicians and Surgeons, New York, NY.

Address correspondence to: Raymond R. Goetz, Ph.D., New York State Psychiatric Institute, 722 West 168th Street, Unit 24, New York, NY 10032.

Received July 22, 1994; revised April 7, 1995; accepted July 27, 1995. that the initial phase of the panic attack is associated with dyspnea.

The symptoms defining the panic attack (DMS-III-R) are largely those of a crescendo of physical distress: palpitations, dyspnea, dizziness, trembling, sweating, choking, nausea, depersonalization, numbness/tingling, flushes, and chest pain. In addition, there are two acute fears, fear of dying and fear of going crazy or doing something uncontrolled. The DMS-III-R criteria state that during panic there should be a discrete period of intense fear or discomfort. Therefore, by this definition, it would be possible to panic but not to experience fear. This possibility is supported by the work of Kushner and Beitman (1990) and Russell et al. (1991) who reported patients with acute crescendos of discomfort, where fear is not prominent, that seem treatable as panic disorder and are exacerbated by lactate infusion. 
In our studies of panicogens we realized that many patients have somatic symptom increases due rather to anticipation, the laboratory situation, and the nonspecific effects of the panicogen than due to the panic crescendo. Therefore, we conservatively defined panic as requiring an abrupt escalation of fear or apprehension accompanied by at least four of the DSM-III-R physical symptoms, as determined by the attending psychiatrist. Physical symptoms alone were not sufficient to establish panic.

In this sample we previously showed (Goetz et al. 1994) that for patients recollecting their "usual" panic the most severe items were not somatic symptoms but, rather, being afraid in general, a desire to flee, difficulty concentrating, and difficulty performing a job. However, the next three ranking symptoms were palpitations, dyspnea, and dizziness or lightheadedness. We also showed that of the somatic symptoms experienced during lactate-induced panic, dyspnea most closely resembled the recollection of "usual" panic symptomatology. The prominence of respiratory symptoms was also reported by Briggs et al. (1993) to be associated with spontaneous panic attacks and a response to imipramine and by McNally et al. (1995) as a powerful discriminator of clinical and nonclinical panic.

In this article we present data on subjective ratings of panic disorder patients undergoing lactate infusion and pursue whether any of the physical symptoms contribute substantially to the determination of panic. As a preliminary step we wanted to compare, via patients subjective reports, how similar lactate-induced panic attacks are to typical or naturally occurring panic attacks. After finding similarities, we wanted to determine which symptoms and fears were most closely related to having a lactate-induced panic attack and to what degree these symptoms contribute to this experience. In particular, we focus on the role of dyspnea, because it is a symptom central to the suffocation false alarm hypothesis (Klein 1993).

Our specific questions were: (1) For patients undergoing lactate infusion, whether they panic or not, how does the lactate infusion experience compare to a typical panic attack? (2) What is the pattern of change for Acute Panic Inventory (API) symptoms? Is there a linear increase in distress or discontinuities such that for some items panic is related to a marked increment. (3) Because increments may be related to baseline status, we also needed to analyze the association of baseline levels to panic status, and then partial out this association from the relationship of symptom increment to panic status to yield a baseline-independent measure of the relation of symptom increment to panic. Multivariate logistic regression techniques were used, providing an integrated, economical description of the contribution of baseline and panic increments of each symptom to the panic/no panic outcome criterion. (4) Are symp- tom increments related to infusate dosage (i.e., the greater the amount of infused sodium lactate, the higher the symptom increments)?

\section{METHODS}

\section{Subjects}

Patients were recruited by media presentations, advertisements, medical referrals, and word of mouth. All patients underwent physical exams and were in good health. They signed informed consent documents after full explanation of the experimental procedures. Patients were excluded if they had concurrent major depressive disorder or current psychoactive drug use that could not be discontinued at least 2 weeks prior to lactate infusion. Patients whose infusions were without procedural difficulties are included in this report. Procedural difficulties included extended infusions with lactate $(>22$ minutes), the occurrence of panic during the preliminary saline placebo infusion, or intravenous infiltration.

The subjects reported about here represent an extended sample from the Liebowitz et al. (1984) sample, and the same subjects reported in Goetz et al. (1994). Seventysix male and 126 female patients with panic disorder $(\mathrm{m} / \mathrm{f}, 48 / 44)$ or agoraphobics with panic attacks $(\mathrm{m} / \mathrm{f}$, $28 / 82$ ), according to DSM-III-R criteria, underwent lactate infusion studies and were serially administered the API during this experimental procedure. The distribution of males and females across the diagnostic categories was significantly different $\left(\mathrm{Chi}^{2}=15.24, \mathrm{df}=1, p<\right.$ .0001 ). Mean ages of the males and females was $33.5 \pm 8$ years and $33.7 \pm 8.3$, respectively (range: 18 to 56 years). Fifty nine percent $(120 / 202)$ of all patients were rated by staff psychiatrists to have experienced a panic attack during the lactate infusion procedure. The mean time to panic was $10.1 \pm 5.9$ minutes (ranging from 1 to $22 \mathrm{~min}$ utes), with the median at 10 minutes.

\section{Procedure}

The procedure used for sodium lactate infusion has been detailed elsewhere (Liebowitz et al. 1984). Briefly, the patients first receives a slow intravenous infusion of normal saline for 30 minutes. Then under single-blind conditions the infusion is switched to half-molar racemic sodium lactate $(10 \mathrm{cc} / \mathrm{kg})$. This is continued for 20 minutes or until the patient experiences a panic attack, at which point the infusion is terminated. A panic attack response designation during an infusion was based on the attending psychiatrist's observation of an abrupt escalation of fear and apprehension or intense desire to flee accompanied by the DSM-III-R physical symptoms for a panic attack (e.g., heart palpitations, shortness of breath, sweating, faintness). Physical symptoms alone were not sufficient to determine panic. 
We used two versions of the API (Dillon et al. 1986), an early version composed of 17 items and a modified version with 12 additional items incorporated after about half of the infusions had been performed. The new items included anxiety symptoms that were mostly unrelated to panic, so as to broaden the possible definition of panic. All API items are DSM-III-R symptoms or symptoms often associated with catecholamine secretion and hypocalcemia or social phobia. Items are rated on a 0 -to- 3 scale $(0=$ symptom not experienced, $1=$ mild, $2=$ moderate, $3=$ severe). The API can be administered in a matter of minutes, and assessments are performed by the staff psychiatrist or psychologist. Patients respond verbally to the API, which is given at four specific time points during the experimental procedure. First, a precatheter placement rating prior to the lead-in saline infusion is given. This is followed by a prelactate rating administered at the end of the saline infusion, immediately prior to the start of the lactate infusion. Two ratings are obtained during the lactate infusion, one at the 10-minute point and a final rating at the end of the infusion (20-minute point). A panic response during the infusion always elicits the final API rating. Thus, if panic is assessed at 0 through 10 minutes of the infusion, the 10-minute API is administered and serves as the termination API. If panic is assessed at $10+$ through 20 minutes, the 20-minute API is administered and serves as the termination API. For patients and subjects completing the 20-minute infusion the 20-minute API serves as the termination API.

At the end of each lactate infusion panic disorder (PD) patients (but not the normal controls) were asked to make subjective ratings of their lactate infusion experiences. They were asked to rate on a 0 -to- 10 scale $(0=$ no anxiety at all, $5=$ moderate levels of anxiety, $10=$ most severe anxiety ever experienced) their baseline and infusion levels of anxiety and apprehension. Three additional ratings on a four-point scale $(0=$ not at all like, $1=$ slightly like, $2=$ moderately like, $3=$ very much like) were to assess the similarity of physical and anxiety symptoms as well as the similarity of their lactate infusion experience to their usual panic attack. A final rating, also on a four-point scale (not, mild, moderate, severe), assessed the subject's overall severity of the lactate infusion experience in comparison to their "usual" panic attack. These subjective ratings were not obtained from all patients; therefore, the reported number of subjects varies slightly.

\section{Data Analysis}

Statistical comparisons were performed among the PD patients across groups as defined by a panic versus a no-panic response to the lactate infusion. Discrete subjective ratings were compared using $\mathrm{Chi}^{2}$ and subjective ratings of anxiety and apprehension from baseline to end of the infusion using a RM-ANOVA (two groups $\times$ two time points). The individual API item difference scores from prelactate to termination of the lactate infusion were compared using an ANOVA for three groups, and pairwise group comparisons were performed using t-test (no corrections for multiple tests were applied).

In these preliminary analyses we found that increases of one point in symptom severity were common. However, increases greater than 1 appeared to be specifically related to panic. Therefore, delta change scores for the API were determined by subtracting the prelactate assessment from the termination scores and were dichotomized as a change of greater than 1 (i.e., 2) versus a change equal to or less than 1 . Two by two distributions of the API item change scores and panic/nopanic response were tested using $\mathrm{Chi}^{2}$ and effect-size statistics (Welkowitz et al. 1982; Borenstein and Cohen 1988; Cohen 1977). Point biserial correlations were performed between the panic/no-panic response and the API prelactate scores, and partial correlations between the change scores and the panic/no-panic response controlling for the prelactate scores. For the exploratory analyses all probability levels were conservatively corrected by dividing the obtained probability level by the number of tests performed [ 29 tests in most cases (Bonferroni technique)]. For significance at the corrected .05 level probabilities had to be at the .0017 level and trends $(p<.10)$ at the .003 level.

Following these analyses we performed a multivariate logistic regression analysis (forward stepwise; SPSS 1990). Because we were assessing the relative importance of the items to the declaration of panic, we chose the items that best distinguished between the panic/nopanic response by exhibiting a significant Bonferronicorrected probability level. We also excluded items that were not reported by at least $20 \%$ of the total sample (increment greater than 1). The symptoms appearing on Table 3 are the symptoms included in the logistic regression analyses and meet these defined criteria. The panic/ no-panic response as rated by the attending psychiatrists was the criterion measure. During the first part of the logistic regression analysis prelactate (baseline) item values were entered stepwise into the model if their probability to enter the equation was at least at the .15 level and remained so after all items were tested for entry. After this segment of the analysis, the dichotomized item change scores (termination minus baseline $=$ $<2$ or $\geqslant 2$ ) were entered in a forward stepwise fashion. Backward stepwise logistic regression procedures were also performed to corroborate the initial forward stepwise results.

In hopes of addressing the issue of sudden onset and explosive symptom increment in relation to a panic/nopanic response, we compared the API 17-item totals across three measurement points (prelactate, 10 minutes into the infusion, end of the infusion at 20 minutes) in a 
RM-ANOVA among four, rather than our original 3, groups. Based on the time at which a panic response was assessed, we further divided the panicking $P D$ patient (PD-P) group into early panic (PD-EP) and late panic (PD-LP) groups (early point of panic $=0$ to 10 minute of infusion; late point of panic $=10+$ to $20 \mathrm{~min}$ utes of infusion). The normal controls and nonpanicking PD (NP-PD) patients remained the same. Physical, cognitive, and fear symptom subscales were calculated and compared in a similar manner. The physical subscale was the computed sum of nine symptom items: Faintness, Palpitations, Dyspnea, Urge to urinate, Urge to defecate, Dizziness/lightheadedness, Sweating, Twitching/trembling, and Nausea. The cognitive subscale was the computed sum of six symptom items: Confused, Sense of unreality, Detached, Difficulty concentrating, Difficulty speaking, and Difficulty performing one's job. The fear subscale was the sum of Afraid of dying and Afraid in general.

One final analysis focused on the notion that symptom increment might be related to the amount of infused lactate (i.e., dose response). As a somewhat imprecise attempt at answering this question, partial correlation coefficients were calculated for the patient groups combined (PD-NP and PD-P) between their symptom increments (termination rating minus the prelactate rating) and the amount of minutes infused, partialing out for their response to the infusion.

\section{RESULT}

\section{Subjective Ratings}

A comparison of the subjective ratings (Tables 1 and 2) of 110 lactate panickers and 74 nonpanickers revealed that $84(76 \%)$ of the lactate panickers compared to 11 $(15 \%)$ of the nonpanickers rated their experience as very much like their usual attacks. Conversely, only 5 of 110 $(4.5 \%)$ lactate panickers rated their experience as only slightly similar to their usual attacks. Furthermore, 92
Table 1. Subjective Ratings among Panic Disorder Patients Undergoing Lactate Infusion ${ }^{a}$

\begin{tabular}{|c|c|c|c|c|}
\hline & \multicolumn{2}{|c|}{ No Panic } & \multicolumn{2}{|c|}{ Panic } \\
\hline & $(\#)$ & $(\%)$ & (\#) & $(\%)$ \\
\hline \multirow{2}{*}{\multicolumn{5}{|c|}{$\begin{array}{l}\text { Typical panic attack } \\
\text { Similarity }^{b}\end{array}$}} \\
\hline & & & & \\
\hline 0 & 13 & (18) & 0 & (0) \\
\hline 1 & 34 & (46) & 5 & (4) \\
\hline 2 & 16 & (22) & 21 & (19) \\
\hline \multirow[t]{2}{*}{3} & 11 & (15) & 84 & (76) \\
\hline & 74 & & 110 & \\
\hline \multicolumn{5}{|c|}{ Overall' } \\
\hline 0 & 7 & (9) & 1 & (1) \\
\hline 1 & 23 & (31) & 2 & (2) \\
\hline 2 & 29 & (39) & 15 & (14) \\
\hline \multirow[t]{2}{*}{3} & 15 & $(20)$ & 92 & (84) \\
\hline & 74 & & 110 & \\
\hline \multicolumn{5}{|c|}{ Symptom similarity } \\
\hline \multicolumn{5}{|c|}{ Physical $^{d}$} \\
\hline 0 & 0 & $(0)$ & 0 & (0) \\
\hline 1 & 10 & (13) & 1 & (1) \\
\hline 2 & 35 & $(47)$ & 9 & $(8)$ \\
\hline \multirow[t]{2}{*}{3} & 29 & (39) & 100 & (91) \\
\hline & 74 & & 110 & \\
\hline \multicolumn{5}{|c|}{ Anxiety ${ }^{e}$} \\
\hline 0 & 10 & (13) & 0 & (0) \\
\hline 1 & 25 & (34) & 2 & (2) \\
\hline 2 & 29 & (39) & 28 & (25) \\
\hline \multirow[t]{2}{*}{3} & 10 & (13) & 80 & (73) \\
\hline & 74 & & 110 & \\
\hline
\end{tabular}

"Similarity: similarity to typical panic attack; overall: overall severity as compared to typical panic attack; physical: similarity ratings of physical; anxiety: anxiety symptoms. $\chi^{2}$ is the test statistic.

${ }^{b} \chi^{2}=87.64, \mathrm{df}=3, p<.0001$.

${ }^{2}=77.95, \mathrm{df}=3, p<.0001$.

${ }^{d} \chi^{2}=56.94, \mathrm{df}=3, p<.0001$.

${ }^{i} \chi^{2}=80.08, \mathrm{df}=3, p<.0001$.

$(84 \%)$ of the lactate panickers rated the overall severity as very similar to their "usual" panic attacks. Both the physical and anxiety symptoms were rated by the vast majority of panicking patients $(91 \%$ and $73 \%$, respec-

Table 2. RM-ANOVA Results for Subjective Ratings of Anxiety and Apprehension at Baseline and at the End of Lactate Infusion

\begin{tabular}{|c|c|c|c|c|c|}
\hline & $\begin{array}{c}\text { Baseline } \\
(X \pm S D)\end{array}$ & $\begin{array}{l}\text { Infusion } \\
(X \pm S D)\end{array}$ & $\begin{array}{l}\text { Panic } \\
(F / \mathrm{df} / p)\end{array}$ & $\begin{array}{c}\text { Time } \\
(F / \mathrm{df} / p)\end{array}$ & $\begin{array}{c}\text { Panic-Time } \\
\text { Interaction } \\
(F / \mathrm{df} / p)\end{array}$ \\
\hline \multicolumn{6}{|l|}{ Anxiety } \\
\hline $\begin{array}{l}\text { Nonpanicking } \\
\text { patients }(n=63)\end{array}$ & $3.30 \pm 1.9$ & $3.49 \pm 2.2$ & $\begin{array}{l}12.18 \\
1 / 149\end{array}$ & $\begin{array}{l}5.10 \\
1 / 149\end{array}$ & $\begin{array}{c}1.26 \\
1 / 149\end{array}$ \\
\hline $\begin{array}{l}\text { Panicking } \\
\text { patients }(n=88)\end{array}$ & $4.12 \pm 1.8$ & $4.69 \pm 2.2$ & 0.001 & 0.025 & NS \\
\hline \multicolumn{6}{|l|}{ Apprehension } \\
\hline $\begin{array}{l}\text { Nonpanicking } \\
\text { patients }(n=63)\end{array}$ & $4.48 \pm 2.4$ & $4.43 \pm 2.6$ & $\begin{array}{c}6.11 \\
1 / 148\end{array}$ & $\begin{array}{l}1.23 \\
1 / 148\end{array}$ & $\begin{array}{c}1.81 \\
1 / 148\end{array}$ \\
\hline $\begin{array}{l}\text { Panicking } \\
\text { patients }(n=87)\end{array}$ & $5.01 \pm 2.2$ & $5.51 \pm 2.2$ & 0.015 & NS & NS \\
\hline
\end{tabular}


Table 3. Acute Panic Inventory (API) Symptom Mean and Standard Deviations (17 items) at Prelactate and Termination of Infusion among Normal Controls (NC), Nonpanicking PD Patients (PD-NP), and Panicking PD Patients (PD-P)

\begin{tabular}{|c|c|c|c|c|c|c|c|c|c|c|}
\hline \multirow[b]{2}{*}{ API Item } & \multicolumn{2}{|c|}{ NC-NP $(n=52)$} & \multicolumn{2}{|c|}{ PD-NP $(n=74)$} & \multicolumn{2}{|c|}{$\operatorname{PD}-\mathrm{P}(n=120)$} & \multicolumn{2}{|l|}{$\begin{array}{c}\text { ANOVA } \\
\text { On } \\
\text { Delta }\end{array}$} & \multicolumn{2}{|c|}{$\begin{array}{c}\text { Pairwise } \\
\text { Comparisons }\end{array}$} \\
\hline & $\begin{array}{c}\text { Prelactate } \\
\text { Mean } \pm \text { SD }\end{array}$ & $\begin{array}{l}\text { Termination } \\
\text { Mean } \pm S D\end{array}$ & $\begin{array}{c}\text { Prelactate } \\
\text { Mean } \pm \text { SD }\end{array}$ & $\begin{array}{l}\text { Termination } \\
\text { Mean } \pm \text { SD }\end{array}$ & $\begin{array}{c}\text { Prelactate } \\
\text { Mean } \pm \text { SD }\end{array}$ & $\begin{array}{l}\text { Termination } \\
\text { Mean } \pm \text { SD }\end{array}$ & $\mathrm{F} / p$ & $\begin{array}{c}\text { NC } \\
\text { vs. } \\
\text { PD-NP }\end{array}$ & $\begin{array}{c}\text { NC } \\
\text { vs. } \\
\text { PD-P }\end{array}$ & $\begin{array}{l}\text { PD-NP } \\
\text { vs. } \\
\text { PD-P }\end{array}$ \\
\hline $\begin{array}{l}\text { Difficulty con- } \\
\text { centrating } \\
\text { Feeling }\end{array}$ & $0.02 \pm 0.14$ & $0.27 \pm 0.60$ & $0.32 \pm 0.68$ & $0.69 \pm 0.91$ & $0.58 \pm 0.83$ & $1.98 \pm 1.12$ & $33.89 \pm 0.0001$ & NS & $* *$ & $* *$ \\
\hline $\begin{array}{l}\text { confused } \\
\text { Fear in }\end{array}$ & $0.00 \pm 0.00$ & $0.10 \pm 0.30$ & $0.08 \pm 0.32$ & $0.39 \pm 0.66$ & $0.29 \pm 0.63$ & $1.39 \pm 1.21$ & $32.70 \pm 0.0001$ & $* *$ & $* *$ & $* *$ \\
\hline $\begin{array}{l}\text { general } \\
\text { Difficulty }\end{array}$ & $0.27 \pm 0.56$ & $0.52 \pm 0.75$ & $0.76 \pm 0.90$ & $1.03 \pm 0.92$ & $1.28 \pm 0.94$ & $2.46 \pm 0.84$ & $28.35 \pm 0.0001$ & NS & $* *$ & $* *$ \\
\hline $\begin{array}{l}\text { speaking } \\
\text { Dyspnea }\end{array}$ & $\begin{array}{l}0.08 \pm 0.39 \\
0.00 \pm 0.00\end{array}$ & $\begin{array}{l}0.40 \pm 0.72 \\
0.40 \pm 0.66\end{array}$ & $\begin{array}{l}0.19 \pm 0.61 \\
0.26 \pm 0.57\end{array}$ & $\begin{array}{l}0.80 \pm 0.99 \\
0.95 \pm 0.90\end{array}$ & $\begin{array}{l}0.27 \pm 0.58 \\
0.55 \pm 0.74\end{array}$ & $\begin{array}{l}1.70 \pm 1.13 \\
1.99 \pm 1.04\end{array}$ & $\begin{array}{l}26.09 \pm 0.0001 \\
24.62 \pm 0.0001\end{array}$ & $\underset{*}{N S}$ & $\begin{array}{l}* * \\
* *\end{array}$ & ** \\
\hline $\begin{array}{l}\text { Dizzy / light- } \\
\text { headed }\end{array}$ & $0.06 \pm 0.23$ & $0.42 \pm 0.64$ & $0.38 \pm 0.61$ & $0.93 \pm 0.96$ & $0.55 \pm 0.82$ & $1.77 \pm 1.14$ & $17.56 \pm 0.0001$ & & & \\
\hline $\begin{array}{l}\text { Fear of } \\
\text { dying }\end{array}$ & $0.00 \pm 0.00$ & $0.00 \pm 0.00$ & $0.07 \pm 0.34$ & $0.04 \pm 0.20$ & $0.18 \pm 0.58$ & $0.65 \pm 1.07$ & $15.86 \pm 0.0001$ & NS & $* *$ & $* *$ \\
\hline $\begin{array}{l}\text { Difficulty } \\
\text { doing job }\end{array}$ & $0.15 \pm 0.46$ & $0.88 \pm 0.92$ & $0.66 \pm 0.93$ & $2.11 \pm 0.99$ & $1.14 \pm 1.02$ & $2.82 \pm 0.58$ & $14.48 \pm 0.0001$ & $* *$ & $* *$ & NS \\
\hline $\begin{array}{l}\text { Twitching/ } \\
\text { trembling }\end{array}$ & $0.13 \pm 0.52$ & $0.83 \pm 1.10$ & $0.51 \pm 0.78$ & $1.76 \pm 1.07$ & $0.74 \pm 0.77$ & $2.37 \pm 0.90$ & $12.47 \pm 0.0001$ & $* *$ & $* *$ & $*$ \\
\hline Palpitations & $0.14 \pm 0.40$ & $0.56 \pm 0.85$ & $0.41 \pm 0.72$ & $1.05 \pm 0.98$ & $0.53 \pm 0.82$ & $1.74 \pm 1.13$ & $12.07 \pm 0.0001$ & NS & $* *$ & $* *$ \\
\hline Faintness & $0.02 \pm 0.14$ & $0.10 \pm 0.41$ & $0.05 \pm 0.23$ & $0.34 \pm 0.65$ & $0.15 \pm 0.46$ & $0.77 \pm 1.10$ & $9.62 \pm 0.0001$ & $*$ & $* *$ & $* *$ \\
\hline $\begin{array}{l}\text { Sense of } \\
\text { unreality }\end{array}$ & $0.02 \pm 0.14$ & $0.08 \pm 0.27$ & $0.09 \pm 0.29$ & $0.38 \pm 0.63$ & $0.22 \pm 0.45$ & $0.70 \pm 1.00$ & $6.02 \pm 0.003$ & $*$ & $* *$ & NS \\
\hline $\begin{array}{l}\text { Sweating } \\
\text { Urge to }\end{array}$ & $0.19 \pm 0.44$ & $0.27 \pm 0.63$ & $0.36 \pm 0.67$ & $0.49 \pm 0.91$ & $0.50 \pm 0.73$ & $1.00 \pm 1.17$ & $5.49 \pm 0.005$ & NS & $* *$ & $* *$ \\
\hline $\begin{array}{l}\text { urinate } \\
\text { Feeling }\end{array}$ & $0.12 \pm 0.43$ & $0.67 \pm 1.10$ & $0.26 \pm 0.55$ & $1.22 \pm 1.20$ & $0.33 \pm 0.66$ & $0.82 \pm 1.17$ & $5.23 \pm 0.006$ & * & NS & $* *$ \\
\hline $\begin{array}{l}\text { detached } \\
\text { Urge to }\end{array}$ & $0.00 \pm 0.00$ & $0.15 \pm 0.46$ & $0.08 \pm 0.32$ & $0.38 \pm 0.75$ & $0.25 \pm 0.51$ & $0.68 \pm 1.04$ & $2.32 \pm 0.101$ & NS & $*$ & NS \\
\hline defecate & $0.02 \pm 0.14$ & $0.02 \pm 0.14$ & $0.01 \pm 0.12$ & $0.11 \pm 0.46$ & $0.05 \pm 0.31$ & $0.08 \pm 0.42$ & $1.02 \pm \mathrm{NS}$ & NS & NS & NS \\
\hline Nausea & $0.00 \pm 0.00$ & $0.33 \pm 0.71$ & $0.11 \pm 0.35$ & $0.42 \pm 0.86$ & $0.17 \pm 0.46$ & $0.53 \pm 0.94$ & $0.08 \pm \mathrm{NS}$ & NS & NS & NS \\
\hline
\end{tabular}

Abbreviations: $\mathrm{NC}=$ normal controls; $\mathrm{NP}=$ nonpanicking; $\mathrm{PD}=$ panic disorder patients; $\mathrm{P}=$ panicking; $\mathrm{NS}=$ nonsignificant.

ANOVA statistics are presented comparing the changes in symptom level from prelactate to termination (delta $=$ termination - prelactate symptom level). ANOVA df $=2 / 243 ;^{*} p<.05 ;{ }^{* *} p<.01$

tively) as very much like their "usual" symptoms. Also interesting was the fact that $39 \%$ of the nonpanicking patients rated their physical symptoms as very similar. All these distributions were significantly different across the response parameter.

Baseline apprehension and anxiety were at mild to moderate levels for both patient groups (nonpanicking and panicking patients). However, these levels increased only slightly (but significantly) from baseline to the rating at the end of the infusion. An RM-ANOVA indicated that the patients significantly differed across the panic (panic/no-panic) and time (baseline and the end of the infusion) parameters for anxiety ratings, the panickers exhibiting higher levels than the nonpanickers. However, both groups increased from baseline to the end of the infusion period. Panickers exhibited higher apprehension levels than nonpanickers, but significant changes from baseline to the end of the infusion were not present. No interactions of panic and time were present.

\section{Acute Panic Inventory}

The ANOVAs performed on the difference scores from prelactate to infusion termination revealed that 14 of the original 17 items significantly differed among the normal controls (NC), the PD-NP patients, and the PD-P patients (Tables 3 and 4).

Eight of the additional 12 items of the modified version of the API also reached statistical significance. Most of these would have maintained their significance even after Bonferroni correction for multiple tests. The fol- 
Table 4. Modified Version Items of the API (12 additional items)

\begin{tabular}{|c|c|c|c|c|c|c|c|c|c|c|}
\hline \multirow[b]{2}{*}{$\begin{array}{l}\text { Modified } \\
\text { API Item }\end{array}$} & \multicolumn{2}{|c|}{ NC-NP $(n=29)$} & \multicolumn{2}{|c|}{ PD-NP $(n=45)$} & \multicolumn{2}{|c|}{ PD-P $(n=67)$} & \multirow{2}{*}{$\begin{array}{c}\text { ANOVA } \\
\text { F/p }\end{array}$} & \multicolumn{3}{|c|}{$\begin{array}{c}\text { Pairwise } \\
\text { Comparisons }\end{array}$} \\
\hline & $\begin{array}{c}\text { Prelactate } \\
\text { Mean } \pm \text { SD }\end{array}$ & $\begin{array}{l}\text { Termination } \\
\text { Mean } \pm \text { SD }\end{array}$ & $\begin{array}{c}\text { Prelactate } \\
\text { Mean } \pm \text { SD }\end{array}$ & $\begin{array}{l}\text { Termination } \\
\text { Mean } \pm \text { SD }\end{array}$ & $\begin{array}{c}\text { Prelactate } \\
\text { Mean } \pm \text { SD }\end{array}$ & $\begin{array}{l}\text { Termination } \\
\text { Mean } \pm S D\end{array}$ & & $\begin{array}{c}\text { NC } \\
\text { vs. } \\
\text { PD-NP }\end{array}$ & $\begin{array}{c}\text { NC } \\
\text { vs. } \\
\text { PD-P }\end{array}$ & $\begin{array}{c}\text { PD-NP } \\
\text { vs. } \\
\text { PD-P }\end{array}$ \\
\hline $\begin{array}{l}\text { Desire to } \\
\text { flee }\end{array}$ & $0.03 \pm 0.19$ & $0.14 \pm 0.44$ & $0.18 \pm 0.44$ & $0.48 \pm 0.85$ & $0.49 \pm 0.80$ & $2.52 \pm 0.77$ & $91.97 \pm 0.0001$ & NS & $* *$ & $* *$ \\
\hline $\begin{array}{l}\text { Fear of losing } \\
\text { control }\end{array}$ & $0.00 \pm 0.00$ & $0.14 \pm 0.44$ & $0.13 \pm 0.50$ & $0.48 \pm 0.82$ & $0.34 \pm 0.71$ & $2.02 \pm 1.09$ & $44.40 \pm 0.0001$ & NS & ** & $* *$ \\
\hline $\begin{array}{l}\text { Chest pain/ } \\
\text { discomfort }\end{array}$ & $0.00 \pm 0.00$ & $0.52 \pm 0.78$ & $0.36 \pm 0.71$ & $0.64 \pm 0.81$ & $0.38 \pm 0.62$ & $1.43 \pm 1.20$ & $10.27 \pm 0.0001$ & NS & * & $* *$ \\
\hline $\begin{array}{l}\text { Fear of going } \\
\text { crazy }\end{array}$ & $0.00 \pm 0.00$ & $0.03 \pm 0.19$ & $0.07 \pm 0.33$ & $0.11 \pm 0.39$ & $0.16 \pm 0.41$ & $0.73 \pm 1.02$ & $10.08 \pm 0.0001$ & NS & $* *$ & $* *$ \\
\hline $\begin{array}{l}\text { Difficulty } \\
\text { swallowing }\end{array}$ & $0.00 \pm 0.00$ & $0.17 \pm 0.47$ & $0.20 \pm 0.50$ & $0.59 \pm 0.87$ & $0.36 \pm 0.64$ & $1.24 \pm 1.19$ & $8.26 \pm 0.0004$ & NS & ** & $* *$ \\
\hline $\begin{array}{l}\text { Feeling } \\
\text { weak }\end{array}$ & $0.07 \pm 0.26$ & $0.52 \pm 0.69$ & $0.40 \pm 0.62$ & $1.00 \pm 1.03$ & $0.75 \pm 0.68$ & $1.89 \pm 1.04$ & $7.47 \pm 0.001$ & NS & $* *$ & $* *$ \\
\hline Dry mouth & $0.48 \pm 0.63$ & $1.41 \pm 0.68$ & $0.65 \pm 0.77$ & $2.20 \pm 0.84$ & $1.28 \pm 0.91$ & $2.43 \pm 0.91$ & $4.57 \pm 0.012$ & $* *$ & NS & $*$ \\
\hline $\begin{array}{l}\text { Tingling } \\
\text { Feel being }\end{array}$ & $0.28 \pm 0.53$ & $1.38 \pm 0.78$ & $0.35 \pm 0.57$ & $1.80 \pm 0.92$ & $0.48 \pm 0.64$ & $2.15 \pm 1.01$ & $3.30 \pm 0.040$ & NS & $*$ & NS \\
\hline $\begin{array}{l}\text { Feel being } \\
\text { watched }\end{array}$ & $0.04 \pm 0.19$ & $0.07 \pm 0.38$ & $0.07 \pm 0.27$ & $0.13 \pm 0.41$ & $0.15 \pm 0.44$ & $0.47 \pm 0.93$ & $2.92 \pm \mathrm{NS}$ & NS & * & * \\
\hline $\begin{array}{l}\text { Hot / cold or } \\
\text { both }\end{array}$ & $0.58 \pm 0.69$ & $1.05 \pm 0.91$ & $1.18 \pm 0.86$ & $1.81 \pm 0.95$ & $1.03 \pm 0.87$ & $1.98 \pm 1.02$ & $1.82 \pm \mathrm{NS}$ & NS & NS & NS \\
\hline $\begin{array}{l}\text { Fear of embar- } \\
\text { rassing self } \\
\text { Feeling }\end{array}$ & $0.07 \pm 0.26$ & $0.07 \pm 0.26$ & $0.07 \pm 0.35$ & $0.21 \pm 0.52$ & $0.29 \pm 0.61$ & $0.46 \pm 0.91$ & $1.00 \pm \mathrm{NS}$ & NS & NS & NS \\
\hline depressed & $0.00 \pm 0.00$ & $0.00 \pm 0.00$ & $0.18 \pm 0.53$ & $0.27 \pm 0.66$ & $0.22 \pm 0.49$ & $0.24 \pm 0.53$ & $0.41 \pm \mathrm{NS}$ & NS & NS & NS \\
\hline
\end{tabular}

Abbreviations: $\mathrm{NC}=$ normal controls; $\mathrm{NP}=$ nonpanicking; $\mathrm{PD}=\mathrm{PD}$ patients; $\mathrm{P}=$ panicking; $\mathrm{NS}=$ nonsignificant. ANOVA $\mathrm{df}=2 / 138 ;{ }^{*} p<.05 ;{ }^{* *} p<.01$.

lowing symptoms did not differ: Urge to defecate, Feeling detached, Nausea, Feeling depressed, Fear of embarrassing self, Feeling of being watched, and Feeling hot, cold, or both. The pairwise comparisons indicated that the PD-P group could be discriminated from the other two groups by the following symptom increments: Feeling faint, Fear of dying, Fear in general, Palpitations, Dyspnea, Dizziness/lightheadedness, Feeling confused, Difficulty concentrating, Sweating, Difficulty speaking, Twitching or trembling, Fear of going crazy, Fear of losing control, Chest pain or discomfort, Difficulty swallowing, Feeling weak, Desire to flee.

Dichotomizing the change scores and using an increment greater than 1 over the baseline as the cut point indicated that after Bonferroni correction 10 of the original 17 and 3 of 12 newer items significantly distinguished between panic and no-panic responses to the sodium lactate infusion (Table 5).

Of particular interest to us was the fact that dyspnea exhibited the highest degree of discrimination among the original 17 API items. Five symptom items exhibited large effect sizes $(\geqslant .80)$ : Desire to flee, Fear of losing control, Dyspnea, Chest Pain, and Feeling confused. Medium effect sizes were exhibited by the remaining nine symptom items (Table 5). Fear of dying and Faintness were good discriminators. However, less than $20 \%$ of the patients reported increments of 2 or greater for these measures.

Table 6 presents the point biserial correlations between prelactate symptom levels and the panic/no-panic response, along with the partial correlations between the dichotomized change (delta) scores and the panic/ no-panic response controlling for the prelactate symptom levels.

A single prelactate symptom, Afraid in general, exhibited a significant point biserial correlation with the panic/ no-panic response. The partial correlations of the change scores were far more revealing, with Desire to flee, Fear of losing control, Afraid in general, and Dyspnea exhibiting the most robust partial correlations $(r \geqslant .40)$.

\section{Symptoms Predicting Panic/No-Panic Outcome}

Ten of the 13 symptom items (Tables 5 and 6) were analyzed in a logistic regression using the forward stepwise technique. Desire to flee, Fear of losing control, and Chest pain, which were not administered to the complete sample, were excluded from this first analysis. Among the prelactate $(\mathrm{P})$ symptom ratings entered at block 1 (Table 7), only Afraid in general and Feeling confused predicted outcome to a significant degree. Palpitations fell just short of reaching the trend level. 
Table 5. API Symptoms That Discriminate between Panic/No-Panic Response to Sodium Lactate Infusion ${ }^{a}$

\begin{tabular}{lccccc}
\hline Symptom & $\begin{array}{c}\text { Panic (\%) } \\
(\boldsymbol{n}=\mathbf{1 1 9})\end{array}$ & $\begin{array}{c}\text { No Panic (\%) } \\
(\boldsymbol{n}=\mathbf{7 7})\end{array}$ & $\boldsymbol{\chi}^{\mathbf{2}}$ & $\boldsymbol{p}^{\boldsymbol{b}}$ & $\begin{array}{c}\text { Effect } \\
\text { Size }\end{array}$ \\
\hline Dyspnea & 51.3 & 11.7 & 31.89 & $0.000^{c}$ & 0.90 \\
Feeling confused & 37.0 & 6.5 & 23.17 & $0.000^{c}$ & 0.79 \\
Afraid in general & 40.3 & 9.1 & 22.61 & $0.000^{c}$ & 0.76 \\
Difficulty speaking & 48.7 & 15.6 & 22.38 & $0.000^{c}$ & 0.73 \\
Difficulty & & & & & \\
$\quad$ concentrating & 47.9 & 15.6 & 21.40 & $0.000^{c}$ & 0.72 \\
Dizzyness/ & & & & & \\
$\quad$ lightheadedness & 43.7 & 14.3 & 18.54 & $0.000^{c}$ & 0.67 \\
Fear of dying & 14.3 & 0 & 12.04 & $0.001^{c}$ & 0.77 \\
Palpitations & 42.0 & 19.5 & 10.71 & $0.001^{c}$ & 0.50 \\
Twitching, & & & & & \\
$\quad$ trembling & 60.5 & 37.7 & 9.77 & $0.002^{d}$ & 0.46 \\
Faintness & 18.5 & 3.9 & 8.94 & $0.003^{d}$ & 0.49
\end{tabular}

$(n=65) \quad(n=45)$

Modified API symptoms added later (\%)

\begin{tabular}{llllll} 
Desire to flee & 74.2 & 8.9 & 45.81 & $0.000^{c}$ & 1.47 \\
Fear of losing & & & & & \\
$\quad$ control & 63.1 & 8.9 & 32.30 & $0.000^{c}$ & 1.23 \\
Chest pain & 40.9 & 6.7 & 15.91 & $0.000^{c}$ & 0.86 \\
\hline
\end{tabular}

${ }^{a}$ Symptoms were dichotomized using an increment of 2 over the prelactate (baseline) symptom level. Post hoc power analysis was used to determine effect size between proportions. Only symptoms reaching the statistical trend level are presented (for $p$ values). Termination ratings were not obtained from six patients. Sample size: 196.

${ }^{b}$ Bonferroni-protected probability levels.

${ }^{c} p<.05$.

${ }^{d} p<.10$.

Among the dichotomized (D) change scores entered at block 2, Afraid in general, Dyspnea, Dizziness/lightheadedness, and Afraid of dying significantly predicted panic/no-panic response. The most robust predictors to panic response were Afraid in general at prelactate and for its change score $[\operatorname{Exp}(B)=3.14$ and 8.54 , respectively], the Dyspnea change score $[\operatorname{Exp}(B)=5.94]$, and the Dizziness/lightheadedness change score $[\operatorname{Exp}(B)=$ 3.77). (See Table 8.) In logistic regression analysis the $\operatorname{Exp}(B)$ is an estimate of the odds ratio. Thus, if a subject's dyspnea rating increased by greater than 1 point, that subject was 5.94 times more likely to be considered a panicker. Logistic regression analysis using the backward stepwise method was performed for model confirmation and yielded the same results.

A subset of the overall patient sample $(N=110)$ had received the modified API with 12 additional symptom items, and we were curious to know how these additional items contributed. Thus, in a second logistic regression (Table 8 ) we analyzed this subset of patients separately, using the same $10 \mathrm{API}$ items plus the three additional items from the modified API (that met inclusion criteria).

Prelactate measure of Afraid in general $[\operatorname{Exp}(B)=$
13.74] and Palpitations $[\operatorname{Exp}(B)=0.22]$ at block 1 were significant predictor of outcome. At analytic block 2, Desire to flee $[\operatorname{Exp}(B)=24.83]$, afraid in general $[\operatorname{Exp}(B)=$ 53.82], Dyspnea $[\operatorname{Exp}(B)=44.73]$, and Fear of losing control $[\operatorname{Exp}(B)=13.67]$ were significant predictors of panic. A backward stepping logistic regression procedure once again corroborated these results, with the addition that the prelactate dyspnea level was entered into the equation at the trend level. Also interesting here is the fact that the estimated odds ratio for palpitations indicated that given a high baseline level of palpitations a patient was 4.5 times less likely to have a panic response.

Because other physical symptoms can be subsumed by or highly correlated with the fearfulness item and as such appear to contribute little to predicting outcome in the logistic regression, in the presence of fearfulness we performed an additional logistic regression using prelactate and dichotomized increment levels, including the physical symptoms only (data not tabled). At the final step, only the baseline levels of Dyspnea $[\operatorname{Exp}(B)=$ 2.58], Feeling detached $[\operatorname{Exp}(B)=3.45]$, and the dichotomous change increments of Dyspnea $[\operatorname{Exp}(B)=11.78]$ and Dizziness/lightheadedness $[\operatorname{Exp}(B)=3.13]$ signifi- 
Table 6. Point Biserial Correlations of Prelactate (baseline) API Symptom Levels with Panic/No-Panic Response to Sodium Lactate Infusion ${ }^{a}$

\begin{tabular}{|c|c|c|c|c|}
\hline \multirow[b]{2}{*}{ Symptom } & \multicolumn{2}{|c|}{$\begin{array}{l}\text { Point Biserial } r \\
\text { Prelactate with } \\
\text { Panic Response } \\
(n=202)\end{array}$} & \multicolumn{2}{|c|}{$\begin{array}{c}\text { Partial } \\
\text { Correlation } \\
\text { Delta }^{b} \\
(n=196)\end{array}$} \\
\hline & $r$ & $p^{c}$ & $r$ & $p^{c}$ \\
\hline Dyspnea & 0.15 & NS & 0.48 & $0.001^{d t}$ \\
\hline Feeling confused & 0.19 & NS & 0.35 & $0.001^{d}$ \\
\hline Afraid in general & 0.26 & $0.001^{d}$ & 0.49 & $0.001^{d}$ \\
\hline Difficulty speaking & 0.03 & NS & 0.35 & $0.001^{d}$ \\
\hline $\begin{array}{l}\text { Difficulty } \\
\text { concentrating }\end{array}$ & \multicolumn{3}{|c|}{ Difficulty } & $0.001^{d}$ \\
\hline \multicolumn{5}{|l|}{ Dizzyness/ } \\
\hline lightheadedness & 0.13 & NS & 0.34 & $0.001^{t}$ \\
\hline Fear of dying & 0.12 & NS & 0.26 & $0.001^{d}$ \\
\hline Palpitations & 0.08 & NS & 0.27 & $0.001^{d}$ \\
\hline \multicolumn{5}{|l|}{ Twitching, } \\
\hline \multirow[t]{3}{*}{ Faintness } & 0.14 & NS & 021 & 0.003 \\
\hline & \multicolumn{2}{|c|}{$(n=110)$} & \multicolumn{2}{|c|}{$(n=108)$} \\
\hline & $r$ & $p$ & $r$ & $p$ \\
\hline \multicolumn{5}{|c|}{ Modified API symptoms } \\
\hline $\begin{array}{l}\text { Desire to flee } \\
\text { Fear of losing }\end{array}$ & 0.24 & NS & 0.70 & $0.001^{d}$ \\
\hline control & 0.18 & NS & 0.57 & $0.001^{d}$ \\
\hline Chest pain & 0.00 & NS & 0.38 & $0.001^{d}$ \\
\hline
\end{tabular}

a Partial correlation of dichotomous change scores with response, controlling for prelactate levels. The same symptoms as in Table 3 are presented for $p$ values. Termination ratings were not obtained from six patients. Sample $n=196$.

${ }^{b}$ Partial correlation of the item increment with panic response with the prelactate item level partialed out.

${ }^{c}$ Bonferroni-protected probability levels.

" $p<.05$.

' $p<.10$.

cantly indicated outcome. The absence of any other physical symptoms, particularly palpitations, chest pain, sweating, and faintness, was surprising.

\section{Symptom Response Characterization}

Plotted on Figures 1 through 4 are group means for the API 17-item total and the physical, fear, and cognitive subscales across three measurements for four groups of subjects. It should be noted that PD-EP patients were not administered the 20-minute API at the end of the infusion (their end of infusion API was administered after the panic assessment during the first 10 minutes of the infusion). Separate RM-ANOVAs supported the notion that there is an additional increment in symptom level associated with panic (statistics available upon request from the authors). In the first set of RM-ANOVAs, four groups were compared, from prelactate to the 10-minute API, and there was a highly significant ( $p<$ .001) group-time interaction. Post hoc analysis revealed that the PD-EP patients were different from every other group, including PD-LP patients. This was true for the API 17-item total and the physical, fear, and cognitive symptom subscales. In the second set of RM-ANOVAs three groups (the early panickers were excluded) were compared, from prelactate to the 10-minute API, to the 20-minute/end-of-infusion API. Once again there was a highly significant group-time interaction. This time PDLP patients differed from the other two groups. Separate trend analysis within each group with three measurements revealed significant linear trends over time for the NC and the PD-NP subjects for all scales. However, PD-LP patients exhibited a significant quadratic trend for the API 17-item total and the cognitive and fear subscales, thus indicating a prepanic acceleration.

\section{Symptom Dose Response to Lactate}

It was suggested that symptom increment may be related to the amount of infused lactate. Thus, we investigated this hypothesis by analyzing the relationship of actual symptom increment and using the amount of time infused with lactate as an imprecise measure of lactate dosage. Within the combined patient group (PD$\mathrm{NP}$ and $\mathrm{PD}-\mathrm{P}$ ) partial correlations were calculated between symptom increments for the 13 symptoms presented on Tables 5 and 6 and the amount of time infused, partialing out for response to the infusion (i.e., panic/no-panic). Two symptom increments exhibited a significant relationship to the amount of time infused, Difficulty speaking (partial $r=-.24, \mathrm{df}=191, p<$ .013 ), and Afraid of losing control (partial $r=-.22$, df $=$ $109, p<.021$ ). Afraid in general exhibited a marginally significant relationship (partial $r=-.18, \mathrm{df}=191, p<$ $.07)$. It would seem from these results that the greater the infused time, the lower the symptom increment, suggesting a possible degree of acclimation to the infusion.

\section{DISCUSSION}

Margraf et al. (1986) in a review of lactate infusion studies reported that the question of similarity between natural panic attacks and attacks induced by lactate infusion "is still open," with only a limited amount of available data at that time addressing this question. To our knowledge, our data represent the largest single cohort of lactate-infused PD subjects, and the question of similarity can be adequately answered. Subjective ratings of the lactate infusion experience provide important preliminary data from which to view the API data. These ratings yield information about the adequacy of the lactate infusion as an experimental model for the natural/spontaneous panic attack as a subjective experience. The vast majority of subjects who were rated by a psychia- 
Table 7. Logistic Regression with Panic/No-Panic Response as the Outcome Measure ${ }^{a}$

\begin{tabular}{|c|c|c|c|c|c|}
\hline & \multicolumn{2}{|c|}{$\begin{array}{l}\text { Improvement } \\
\text { of Model }\end{array}$} & \multirow{2}{*}{$\begin{array}{c}\text { Correct } \\
\text { Response } \\
(\%)\end{array}$} & & \\
\hline & $F$ & $p$ & & & \\
\hline \multicolumn{6}{|l|}{ Block 1} \\
\hline Afraid in general & 15.07 & 0.0001 & 67 & & \\
\hline Feeling confused & 5.58 & 0.0182 & 68 & & \\
\hline \multicolumn{6}{|l|}{ Block 2} \\
\hline Afraid in general & 46.56 & 0.0001 & 77 & & \\
\hline Dyspnea & 22.29 & 0.0001 & 81 & & \\
\hline \multicolumn{6}{|l|}{ Dizzyness/ } \\
\hline lightheadedness & 8.85 & 0.0029 & 78 & & \\
\hline Afraid of dying ${ }^{b}$ & 5.55 & 0.0184 & 79 & & \\
\hline \multirow[t]{2}{*}{ Palpitations } & 2.26 & 0.133 & 81 & & \\
\hline & \multicolumn{5}{|c|}{ Statistics for Variables in the Equation at Last Step } \\
\hline Symptom & Wald & df & Significant & $R$ & $\operatorname{Exp}(B)$ \\
\hline Afraid in general $(\mathrm{P})^{c}$ & 21.96 & 1 & 0.000 & 0.287 & 3.14 \\
\hline Confused $(\mathrm{P})$ & 4.13 & 1 & 0.043 & 0.094 & 2.88 \\
\hline \multicolumn{6}{|l|}{ Feeling afraid in } \\
\hline Dyspnea (D) & 12.69 & 1 & 0.001 & 0.210 & 5.94 \\
\hline \multicolumn{6}{|l|}{ Dizzyness/ } \\
\hline lightheadedness (D) & 7.25 & 1 & 0.007 & 0.147 & 3.77 \\
\hline Palpitation (D) & 2.23 & 1 & 0.135 & 0.031 & 2.01 \\
\hline
\end{tabular}

\footnotetext{
"In the first analytic block (Block 1) 10 prelactate symptom values (i.e., from the original 17 -item API) were forward-stepped into a logistic regression analysis. At Block 2 the dichotomized increment scores for the same 10 symptoms were forward-stepped. Probability to enter the equation at each step was set at the .15 level. Sample $=196$.

${ }^{b}$ Afraid of dying was excluded from the statistics at the last step because no nonpanicker exhibited a change score of 2 or greater

C $\mathrm{P}=$ prelactate symptom level.

${ }^{d} \mathrm{D}=$ dichotomized increment over prelactate level.
}

trist as having experienced a DSM-III-R panic attack rated these attacks as very similar to their typical panic attack. The overall severity level was very similar, and both the physical and anxiety symptoms were overwhelmingly rated as similar. However, it should also be pointed out that a substantial minority of the nonpanickers also rated the lactate infusion experience as similar to their "usual" panic attacks.

Baseline and postinfusion ratings of anxiety and apprehension levels were never greater than the mild to moderate level for both patient groups, and the increase from baseline to postinfusion was less than dramatic and did not differ across the panic response (interaction of panic and time). As noted by Margraf et al. (1986), "there are no data to demonstrate that lactate produces the explosive onset of anxiety regarded as characteristic of panic attack." However, this less-than-dramatic change integrated with the similarity data suggests that the typical panic attack experienced by our PD patients only reaches moderate levels of anxiety and apprehension. Therefore, Beitman's description of nonfearful panic is more readily comprehensible. That the "usual" panic is not highly fearful does not mean that some attacks, in particular the initial panics, are not terrifying.

As stated at the outset we wanted to determine which symptoms and fears were most closely related to having a lactate-induced panic attack and to what degree these symptoms contribute to this experience. Preliminary analyses suggested that changes in symptom levels of one step were common. However, increments of more than one level were more specifically related to a panic response during lactate infusion. This is evident from an examination of the symptom means from prelactate to termination (Tables 3 and 4) and the pairwise comparison of the PD-NP and PD-P deltas. Although for most API symptom items (Table 5) there were significant distribution differences for increments greater than 1 across the panic/no-panic response, only Desire to flee, Fear of losing control, Chest pain, and Dyspnea exhibited large effect sizes. Other physical symptoms, such as Palpitations, Dizziness/lightheadedness, and Twitching/trembling, all showed some degree of discrimination, but not to the degree exhibited by Dyspnea and Chest pain. 
Table 8. Logistic Regression with Panic/No-Panic Response as the Outcome Measure ${ }^{a}$

\begin{tabular}{|c|c|c|c|c|c|}
\hline & \multicolumn{2}{|c|}{$\begin{array}{l}\text { Improvement } \\
\text { of Model }\end{array}$} & \multirow{2}{*}{$\begin{array}{c}\text { Correct } \\
\text { Response (\%) }\end{array}$} & & \\
\hline & $F$ & $p$ & & & \\
\hline \multicolumn{6}{|l|}{ Block 1} \\
\hline Afraid in general $(\mathrm{P})^{b}$ & 11.29 & 0.001 & 70 & & \\
\hline Palpitations $(\mathrm{P})$ & 2.56 & 0.110 & 70 & & \\
\hline \multicolumn{6}{|l|}{ Block 2} \\
\hline Desire to flee $(D)^{c}$ & 48.53 & 0.0001 & 84 & & \\
\hline Afraid in general (D) & 20.67 & 0.0001 & 90 & & \\
\hline Dyspnea (D) & 8.78 & 0.003 & 91 & & \\
\hline \multicolumn{6}{|l|}{ Afraid of losing } \\
\hline control (D) & 7.75 & 0.006 & 92 & & \\
\hline \multirow[t]{2}{*}{ Feeling faint (D) } & 2.14 & 0.143 & 91 & & \\
\hline & \multicolumn{5}{|c|}{ Statistics for Variables in the Equation at Last Step } \\
\hline Symptom & Wald & df & Significance & $R$ & $\operatorname{Exp}(B)$ \\
\hline Afraid in general $(P)$ & 14.08 & 1 & 0.001 & 0.299 & 13.74 \\
\hline Palpitations $(\mathrm{P})$ & 5.88 & 1 & 0.016 & -0.170 & 0.22 \\
\hline Desire to flee (D) & 9.97 & 1 & 0.002 & 0.243 & 24.83 \\
\hline Afraid in general (D) & 7.94 & 1 & 0.005 & 0.210 & 53.82 \\
\hline Dyspnea (D) & 7.53 & 1 & 0.007 & 0.202 & 44.73 \\
\hline \multicolumn{6}{|l|}{ Fear of losing } \\
\hline control (D) & 6.90 & 1 & 0.009 & 0.190 & 13.67 \\
\hline Feeling faint (D) & 2.22 & 1 & 0.137 & -0.040 & 0.17 \\
\hline
\end{tabular}

\footnotetext{
${ }^{a}$ In the first analytic block 13 API symptoms (i.e., the same ten as in Table 5 plus three of the newer prelactate symptom values) were forward-stepped into a logistic regression analysis. At Block 2 the dichotomized change scores for the same 13 symptoms were forward-stepped. Probability to enter the equation at each step was set at the .15 level. Sample $=110$.

${ }^{b} \mathrm{P}=$ prelactate symptom level.

${ }^{c} \mathrm{D}=$ dichotomized increment over prelactate level.
}

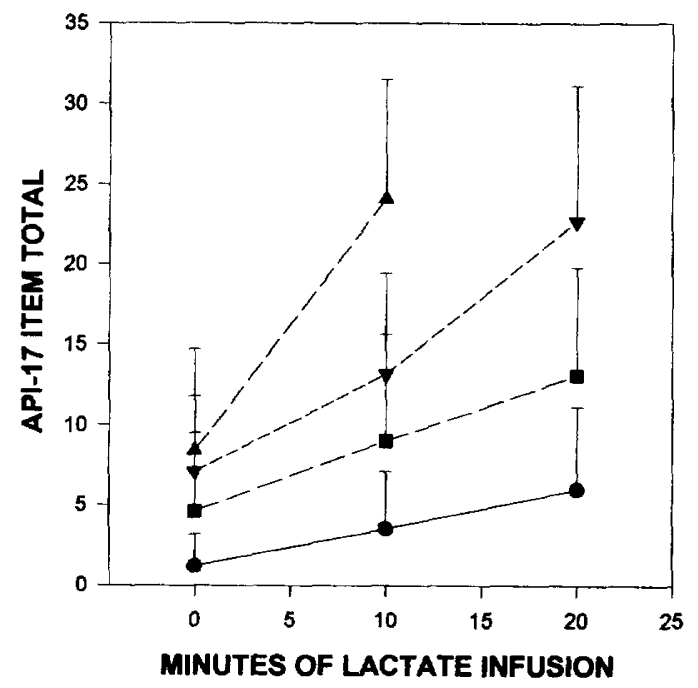

Figure 1. API: 17 -item total at preinfusion, 10 minutes, and 20 minutes of lactate infusion. NC: normal controls $(n=52)$; PD-NP: nonpanicking PD patients ( $n=74)$; PD-EP: early PD panickers $(n=66)$; PD-LP: late PD panickers $(n=54)$.
Using correlational analysis we find that the relationship of baseline API levels to panic status was relatively unrevealing, with only the item Afraid in general attaining significance, thus confirming a previous report (Liebowitz et al. 1984). However, the absolute magnitude of this relationship was modest $(r=.26, \mathrm{df}=200$, Bonferroni-protected $p<.05$ ).

Analyzing the relationship of API increment to panic status while partialing out the baseline levels showed a large number of items significantly related to a panic/ no-panic response. Most notable among these were Afraid in general, Dyspnea, Desire to flee, and Fear of losing control. Because the increment measure and the partialed measures of change are both independent of the baseline symptom level, this finding refutes the argument that the panic phenomenon is a simple additive increment of distress on to a high baseline (Margraf et al. 1986). Similarly, Zandbergen et al. (1991) reported that during a $35 \% \mathrm{CO}_{2}$ challenge, dyspnea yielded the highest net value of all DSM-III-R symptoms, and high correlations were found between dyspnea and experienced anxiety during both $35 \% \mathrm{CO}_{2}$ and hyperventilation challenges. Correlational analysis did not reveal 


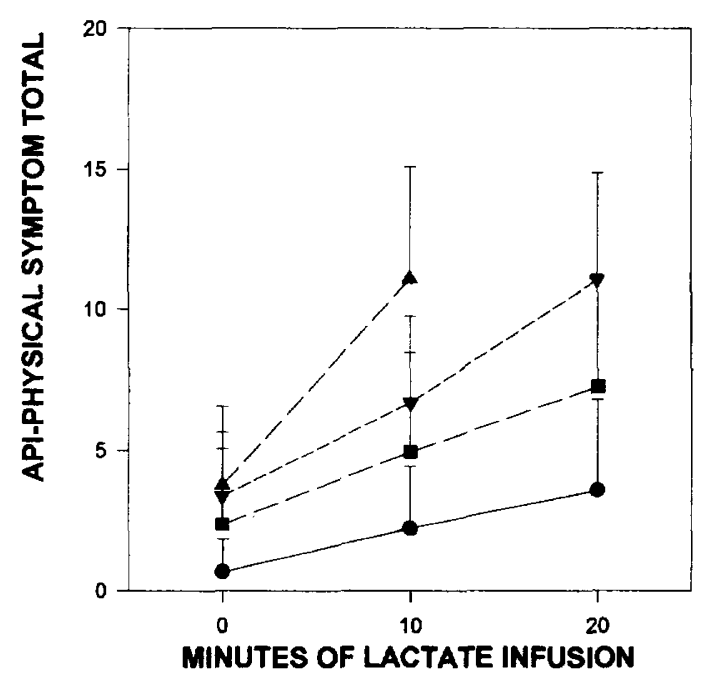

Figure 2. API: Physical symptom total at preinfusion, 10 minutes, and 20 minutes of lactate infusion. NC: normal controls $(n=52)$; PD-NP: nonpanicking PD patients $(n=74)$; PD-EP: early PD panickers $(n=66)$; PD-LP: late PD panickers $(n=54)$.

any positive relationship between raw symptom increment and amount of time infused (i.e., infused lactate dose response) either.

To study the unique independent contribution of each API symptom to the declaration of panic we used logistic regression analysis. Results showed that the increments in two physical symptoms, Dyspnea and Dizziness/ lightheadedness, added significantly to the discrimination between panic and no-panic assessments over and above both baseline variables and the variables reflecting fearfulness with the exception of baseline confu-

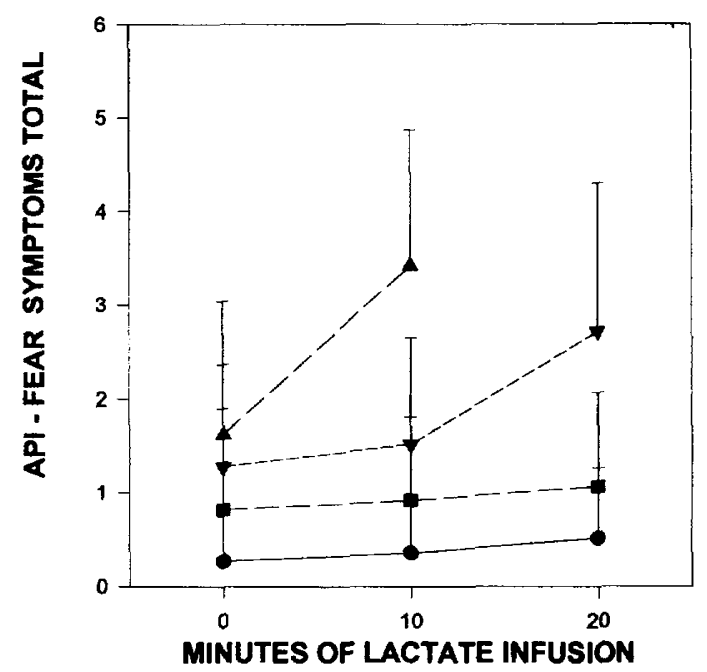

Figure 3. API: Fear in general and fear of dying: cognitive symptom total at preinfusion, 10 minutes, and 20 minutes of lactate infusion. NC: normal controls $(n=52)$; PD-NP: nonpanicking PD patients ( $n=74)$; PD-EP: early PD panickers $(n=66)$; PD-LP: late PD panickers $(n=54)$.

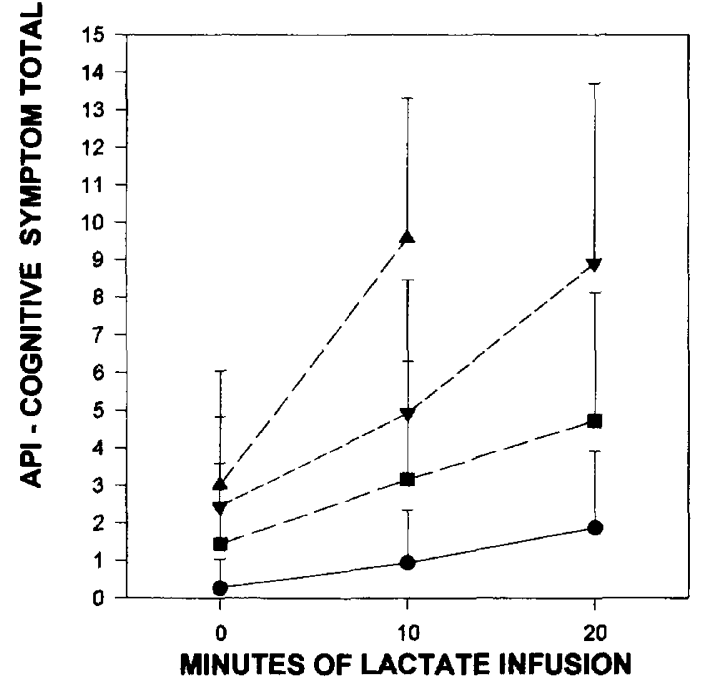

Figure 4. Mean API: cognitive symptom totals at preinfusion, 10 minutes, and 20 minutes of lactate infusion. NC: normal controls ( $n=52$ ); PD-NP: nonpanicking PD patients $(n=74)$; PD-EP: early PD panickers $(n=66)$; PD-LP: late PD panickers $(n=54)$.

sion. The results of the subgroup logistic regression analysis, including the three additional symptoms from the modified API, were essentially the same, except for the addition of baseline palpitations and the increments of desire to flee and fear of losing control.

The pairwise comparisons appearing on Tables 3 and 4 show that many physical and cognitive symptoms significantly discriminate between the panic and nopanic response of PD patients. However, their relationship to the assessed response is subsumed under Afraid in general, Dyspnea, and Dizziness/lightheadedness. In addition to their independent contributions exhibited by the logistic regression analysis, Dyspnea and Dizziness/lightheadedness were modestly correlated with each other among all PD patients after partialing for the panic/no-panic response ( $r=.27, \mathrm{df}=191, p<$ .001 ). Because dizziness/lightheadedness is a symptom frequently reported in association with hyperventilation, it is a confirmation of the suffocation false alarm theory that other outstanding physical symptoms such as palpitations, trembling, sweating, nausea, depersonalization, numbness/tingling, flushing, and chest pain proved superfluous to declaring panic and made no significant independent contribution. Klein (1993) emphasized that symptoms such as palpitations, trembling, and sweating are the common accompaniments of fear, which must be distinguished from panic as it occurs in panic disorder, which is not to say that these are never associated with panic. Rather, it follows from the suffocation false alarm theory that these symptoms should not be distinctively related to panic-and in fact are not during lactate challenge. 
Analysis of the API 17-item total and the cognitive, fear, and physical subscales over the course of the infusion indicates that there is an additional increment in symptom levels that is associated with the panic assessment and might be described as explosive. In a recent report (Goetz et al. 1993) time-specific, dramatic changes in respiratory function were shown to be associated with closely approaching panic (within 2-3 minutes) and the point of panic among PD patients experiencing laboratory attacks during the preliminary saline infusion. Preliminary objective ambulatory respiration measurements show sharp increases in tidal volume during panic, and this procedure shows promise as a specific diagnostic technique analogous to the Holter monitor.

To sum up lactate-induced panics are considered by patients as very similar to usual clinical panics, which on average, may be no more moderate in severity. However, it is fear in general and desire to flee (as per panic assessment criteria) and dyspnea with dizziness/lightheadedness sensations that are most distinctive, with features such as fear of dying being very specific, but rather uncommon. All other physical indicators of panic were subsumed primarily under Dyspnea and secondarily under Dizziness-lightheadedness. Because we did not use dyspnea as a defining criterion feature of panic, its salience is consonant with the suffocation false alarm theory of panic.

\section{REFERENCES}

Borenstein M, Cohen J (1988): Statistical Power Analysis: A Program. Hillsdale, NJ, Erlbaum

Briggs AC, Stretch DD, Brandon S (1993): Subtyping of panic disorder by symptom profile. Brit J Psychiatry 163:201209

Cohen J (1977): Statistical Power Analysis for the Behavioral Sciences. New York, Academic Press

Dillon D, Gorman JM, Liebowitz MR, Fyer AJ, Klein DF
(1986): Measurement of lactate-induced panic and anxiety. Psychiatr Res 20:97-105

Goetz RR, Klein DF, Gully R, Kahn J, Liebowitz MR, Fyer AJ, Gorman JM (1993): Panic attacks during placebo procedures in the laboratory: Physiology and symptomatology. Arch Gen Psychiatry 50:280-285

Goetz RR, Klein DF, Gorman JM (1994): Consistencies between recalled panic and lactate-induced panic. Anxiety 1:1, 31-36

Katerndahl DA (1988): The sequence of panic symptoms. J Fam Practice 26(1):49-52

Klein DF (1993): False suffocation alarms, spontaneous panics, and related conditions: An integrative hypothesis. Arch Gen Psychiatry 50:306-317

Kushner MG, Beitman BD (1990): Panic attacks without fear: An overview. Behav Res Ther 28:6,469-479

Liebowitz MR, Fyer AJ, Gorman JM, Dillon D, Appleby IL, Levy G, Anderson S, Levitt M, Palij M, Davies SO, Klein DF (1984): Lactate provocation of panic attacks: I. Clinical and behavioral findings. Arch Gen Psychiatr 41:764770

Margraf J, Ehlers A, Roth WT (1986): Sodium lactate infusions and panic attacks: A review and critique. Psychosom Med 48:1/2:23-51

McNally RJ, Hornig CD, Donnell CD (1995): Clinical versus nonclinical panic: A test of suffocation false alarm theory. Behav Res Ther 33:2, 127-131

Russell JL, Kushner MG, Beitman BD, Bartels KM (1991): Nonfearful panic disorder in neurology patients validated by lactate challenge. Am J Psychiatry 148:361-364

Statistical Package for the Social Sciences (SPSS) (1990): SPSS Reference Guide, SPSS Release 4. Chicago, IL, SPSS

Welkowitz J, Ewen RB, Cohen J (1982): Introductory Statistics for the Behavioral Sciences, ed. 3. Orlando, FL, Academic

Zandbergen J, Pols H, Fernandez I, Griez E (1991): An analysis of panic symptoms during hypercarbia compared to hypocarbia in patients with panic attacks. J Affect Dis 23:131-136 